\title{
Adsorption and desorption behavior of water and organic vapor of allophanic soil-templated porous carbon materials
}

\author{
Hironobu ABIKO ${ }^{\dagger}$ \\ Work Environment Research Group, National Institute of Occupational Safety and Health, Japan (JNIOSH), \\ 6-21-1 Nagao, Tama-ku, Kawasaki 214-8585, Japan
}

\begin{abstract}
We have synthesized several kinds of porous carbon material by template method using 2 kinds of natural allophanic soil purchased in Japan as template materials. To determine the hydroscopic properties of the templated porous carbon specimens, we measured their water adsorption and desorption isotherms around room temperature $(283,293$ and $298 \mathrm{~K})$. We also measured porous and chemical properties of the templated porous carbon specimens, and investigated the relationships between pore development and their water isotherms. The features of the isotherm curves of the templated porous carbon specimens were different from those of common activated carbon used as a reference, and the features in this study were dependent on template materials rather than carbon ingredients. Some of the templated porous carbon specimens had water adsorption isotherms that rose sharply at approximately $80 \%$ relative humidity $(\mathrm{RH})$, and the desorption isotherms dropped off at $60 \% \mathrm{RH}$. The results indicate the possibility of application of these specimens as effective adsorbents that are not susceptible to moisture as compared with common activated carbon. The specimens are also assumed to be useful as humidity control materials.
\end{abstract}

(C2012 The Ceramic Society of Japan. All rights reserved.

Key-words : Allophanic soil template, Hysteresis, Organic vapor adsorption, Porous carbon material, Relative humidity, Water isotherm

[Received June 11, 2012; Accepted September 11, 2012]

In both industrial applications and occupational hygiene, activated carbon is used as an adsorbent for various kinds of organic vapor. Particularly, coconut shell activated carbon is a commonly used material for gas adsorption in Japan. Also many other types of porous carbon product are produced from various raw materials with various configurations and specific surface areas, and they have preferable adsorption ability and capacity for typical organic vapors or gaseous compounds compared with other porous materials. The adsorption capacities of activated carbon are affected by temperature, flow rate of sampled air, concentrations of representative organic vapors and the moisture contents in both the airflow and the activated carbon. Among these factors, the moisture contents have been the focus of many quantitative studies, because in many cases moisture adsorption reduces the gaseous adsorption capacities. Accordingly, there have been many experimental reports regarding the moisture effect on activated carbon around room temperature (approximately 293-298 K). ${ }^{1)-12)}$ With regard to various porous carbon materials, their water adsorption and desorption behavior and their mechanism are also attractive from the viewpoint of surface science. ${ }^{13)-17)}$

In previous studies, ${ }^{18)-20)}$ we synthesized templated porous carbon materials ${ }^{21-27)}$ using silica gels ${ }^{20)}$ and natural allophanic soils ${ }^{18)-20)}$ or minerals ${ }^{20)}$ purchased in Japan as template materials. The templated porous carbon specimens each have unique pore size distributions and pore development characteristics based on template materials, and effective adsorption abilities and capacities against several kinds of organic vapor compared with common coconut shell activated carbon. In this study, to understand the hydroscopic properties of the templated porous carbon

\footnotetext{
Corresponding author: H. Abiko; E-mail: abiko-h@umin.ac.jp
}

specimens mentioned above, we measured their water adsorption and desorption isotherms around room temperature. We also measured their chemical and porous properties, and investigated the relationships between the properties of the isotherms.

We synthesized templated porous carbon specimens with reference to the method described previously, ${ }^{18), 19)}$ and the carbon specimens were carbonized at $973 \mathrm{~K}$ or $1173 \mathrm{~K}$. We used $\mathrm{D}(+)$-glucose, furfuryl alcohol (products of Wako Pure Chemical Industries Ltd.), and brown sugar (made from sugarcane, product of Okinawa Kokuto Co. Ltd.) as carbon ingredients and 2 kinds of natural allophanic soil purchased in Japan (as garden supplies marketed by Seiwa Pro Co. Ltd.) as template materials. The features of the allophanic soils are similarly as described in the previous report. ${ }^{18)} \mathrm{D}(+)$-glucose and brown sugar were used as aqueous solution (approximately $60 \mathrm{~g}$ of each object substance was dissolved in $100 \mathrm{ml}$ of ultrapure water). Soaking period of the template material in the brown sugar aqueous solution was 7 days.

The water isotherms of the specimens were measured by BELSORP-max-12-N-VP (BEL JAPAN Inc.) using only ultrapure water after degassing. We defined the data point at which it attained equilibration as that when the pressure change of water in $300 \mathrm{~s}$ was within $0.3 \%$ of the indicated value. The isotherms were measured at 283, 293 and $298 \mathrm{~K}$, and the temperature was controlled using a thermo-controlled cooling pump type CTP1000 (Tokyo Rikakikai Co. Ltd.) with accuracy of $\pm 0.7 \mathrm{~K}$. The isotherms of nitrogen at $77 \mathrm{~K}, \mathrm{~N}_{2}$-BET specific surface area, pore size distributions and pore volumes of the specimens were also measured by the BELSORP-max apparatus with $\mathrm{N}_{2}$ gas $(\geq 99.99995 \%)$ by its high accuracy measurement mode with $\mathrm{ASFM}^{\mathrm{TM}}$. Pore size distributions and pore volumes were calculated by the MP method (microporous region) and the Dolli- 


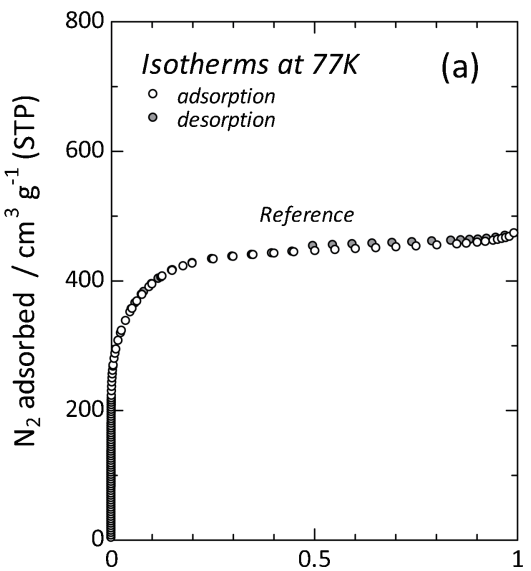

Relative Pressure

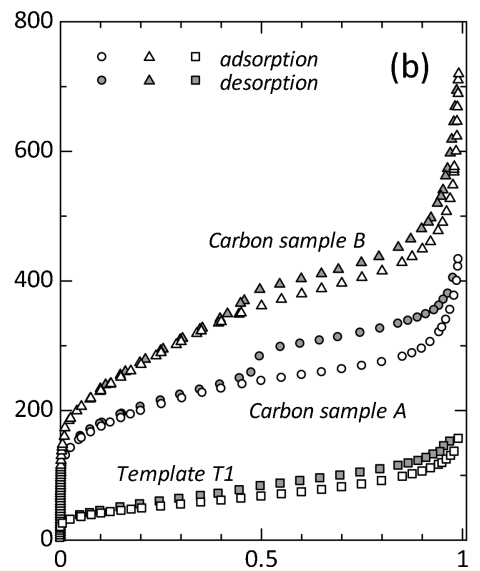

Relative Pressure

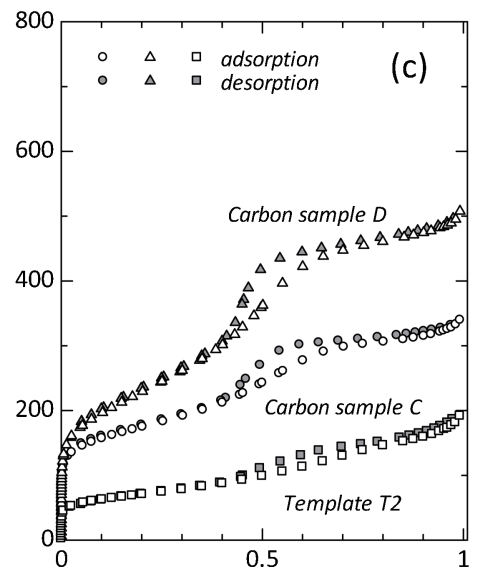

Relative Pressure

Fig. 1. $\mathrm{N}_{2}$ adsorption and desorption isotherms of the reference, templated porous carbon specimens and template materials in this research at 77 K. STP: Standard Temperature and Pressure.

Table 1. $\mathrm{N}_{2}$-BET specific surface areas, porous properties of the template materials, the reference and templated porous carbon specimens used in this study

\begin{tabular}{|c|c|c|c|c|c|c|c|}
\hline Sample & - & - & Reference & $\mathrm{A}$ & $\mathrm{B}$ & $\mathrm{C}$ & $\mathrm{D}$ \\
\hline Template & $\mathrm{T} 1$ & $\mathrm{~T} 2$ & - & $\mathrm{T} 1$ & $\mathrm{~T} 1$ & $\mathrm{~T} 2$ & $\mathrm{~T} 2$ \\
\hline Carbon ingredient & - & - & Coconut shell & Furfuryl alcohol & Brown sugar & Furfuryl alcohol & Glucose \\
\hline $\begin{array}{l}\text { Carbonization } \\
\text { temperature } / \mathrm{K}\end{array}$ & - & - & - & 973 & 1173 & 973 & 1173 \\
\hline $\begin{array}{l}\mathrm{N}_{2}-\text { BET specific } \\
\text { surface area } / \mathrm{m}^{2} \mathrm{~g}^{-1}\end{array}$ & 209 & 247 & 1530 & 690 & 950 & 615 & 811 \\
\hline$V_{\text {micro }} / \mathrm{cm}^{3} \mathrm{~g}^{-1}$ & 0.082 & 0.146 & 0.718 & 0.328 & 0.477 & 0.437 & 0.641 \\
\hline$V_{\text {meso }} / \mathrm{cm}^{3} \mathrm{~g}^{-1}$ & 0.091 & 0.219 & 0.138 & 0.315 & 0.544 & 0.372 & 0.663 \\
\hline $\begin{array}{l}\text { Average pore width } \\
\text { by t-method/nm }\end{array}$ & 1.078 & 1.717 & 0.843 & 1.088 & 1.295 & 1.341 & 1.763 \\
\hline True density $/ \mathrm{g} \mathrm{cm}^{-3}$ & $\begin{aligned} 1.892 & \pm 0.002 \\
\mathrm{~N} & =5\end{aligned}$ & $\begin{aligned} 2.153 & \pm 0.001 \\
\mathrm{~N} & =5\end{aligned}$ & $\begin{array}{c}1.905 \pm 0.003 \\
\mathrm{~N}=7\end{array}$ & $\begin{array}{c}1.643 \pm 0.002 \\
\mathrm{~N}=6\end{array}$ & $\begin{array}{c}1.928 \pm 0.014 \\
\mathrm{~N}=3\end{array}$ & $\begin{array}{c}1.665 \pm 0.002 \\
\mathrm{~N}=5\end{array}$ & $\begin{array}{c}2.132 \pm 0.004 \\
\mathrm{~N}=6\end{array}$ \\
\hline
\end{tabular}

$V_{\text {micro }}$ is micropore volume calculated by the MP method, and $V_{\text {meso }}$ is mesopore volume calculated by the D-H method.

more-Heal (D-H) method (mesoporous region). We also calculated average pore width by the $t-$ method. Drying pretreatment under vacuum for each specimen was carried out at $393 \mathrm{~K}$ for approximately $30 \mathrm{~min}$ by BELPREP-vac II (BEL JAPAN Inc.). With regard to chemical and porous properties of the specimens, we performed elemental analysis for $\mathrm{CHN}$ with a PerkinElmer 2400 II CHNS/O analyzer. Ash measurements were carried out with a PerkinElmer AD 6 microbalance and a combustion condition of $773 \mathrm{~K}$ in air in Muffle Furnace FP 100 (Yamato Scientific Co., Ltd.). We measured the true density of the specimens using Micromeritics multi-volume pycnometer 1305 with He gas $(\geq 99.99995 \%)$. In addition, we used a common coconut shell activated carbon material as reference.

We also measured adsorption and desorption isotherms of cyclohexane vapor at $293 \mathrm{~K}$ on the specimens. Cyclohexane was obtained from Wako Pure Chemical Industries Ltd., and measurement method and conditions were similar in the case of water isotherms as described above.

Figure 1 shows $\mathrm{N}_{2}$ adsorption and desorption isotherms at $77 \mathrm{~K}$ of the reference and the templated porous carbon specimens. The template materials $\mathrm{T} 1$ (soil consists of allophane and quartz) and T2 (volcanic ash soil consists of allophane and wollastonite) are identical with the templates described previously, ${ }^{18), 19)}$ and the carbon specimens A, C and D are corresponding to the specimens $\mathrm{SA} 4{ }^{19)} \mathrm{S} 3$ and $\mathrm{S} 5^{18)}$ in the previous reports. The reference showed no hysteresis in the isotherm [Fig. 1 (a)]. It had a type I isotherm as defined by IUPAC, ${ }^{28), 29)}$ which is characteristic for $\mathrm{N}_{2}$ isotherms of microporous materials. In contrast, the 4 templated porous carbon specimens (samples A-D) showed hysteresis between adsorption and desorption processes [Figs. 1(b) and 1(c)]. The isotherm curves were classified as type IV isotherms, which is a characteristic feature of mesoporous carbon materials.

Table 1 shows the micropore volumes $\left(V_{\text {micro }}\right)$ and mesopore volumes $\left(V_{\text {meso }}\right)$ of the reference and templated porous carbon specimens measured with $\mathrm{N}_{2}$ gas. Micropores contribute to adsorption capacity of adsorbates in porous materials, and this is similarly applicable to mesoporous carbon materials. All of the templated porous carbon specimens had effective pore development both in the microporous and the mesoporous region. The $\mathrm{N}_{2}$-BET specific surface areas of the templated porous carbon specimens ranged from 615 to $950 \mathrm{~m}^{2} / \mathrm{g}$. These values were slightly smaller than that of the reference, but these observations indicated that the method for synthesis in this study was applicable for preparing porous carbon materials with sufficiently high specific surface areas for gas adsorption. Figure 2 shows water isotherms at $293 \mathrm{~K}$ of the reference and templated porous carbon specimens. The horizontal axes in Fig. 2 represent relative humidity, which is the value of water pressure divided by saturated water pressure at each temperature. The vertical axes 

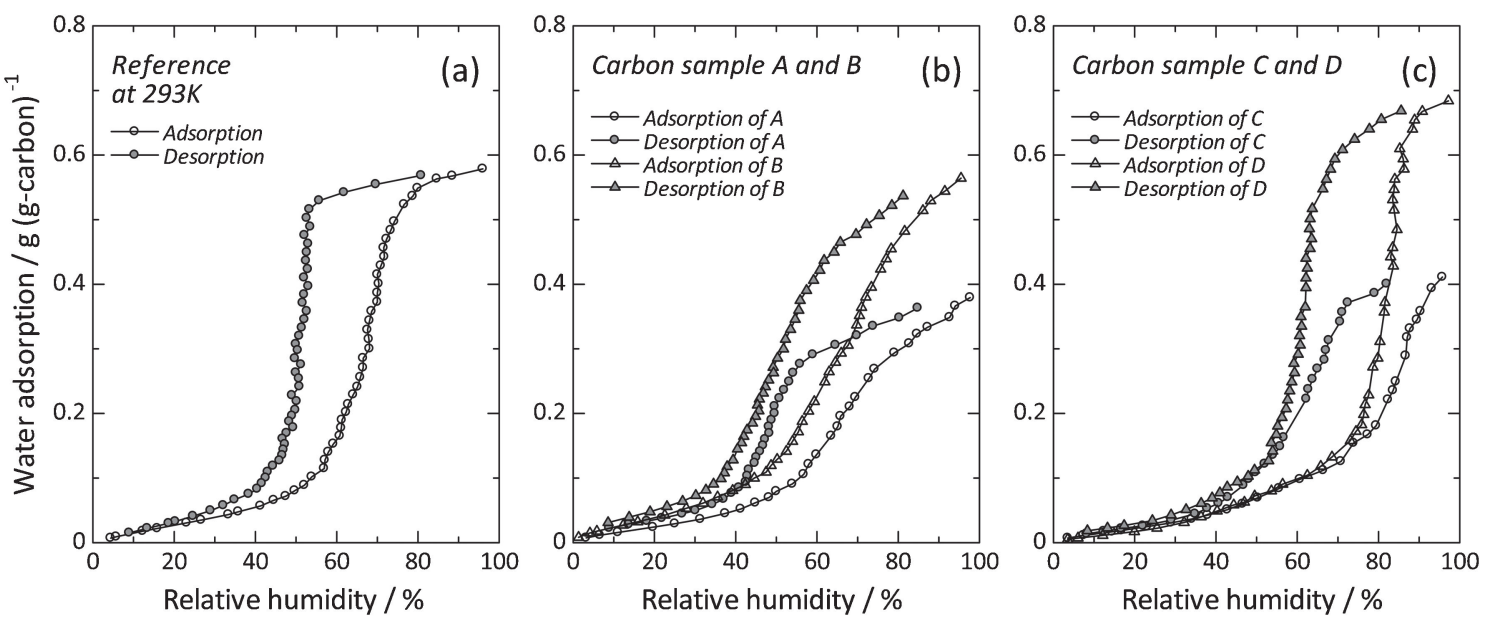

Fig. 2. Water adsorption and desorption isotherms of the reference and templated porous carbon specimens at $293 \mathrm{~K}$.
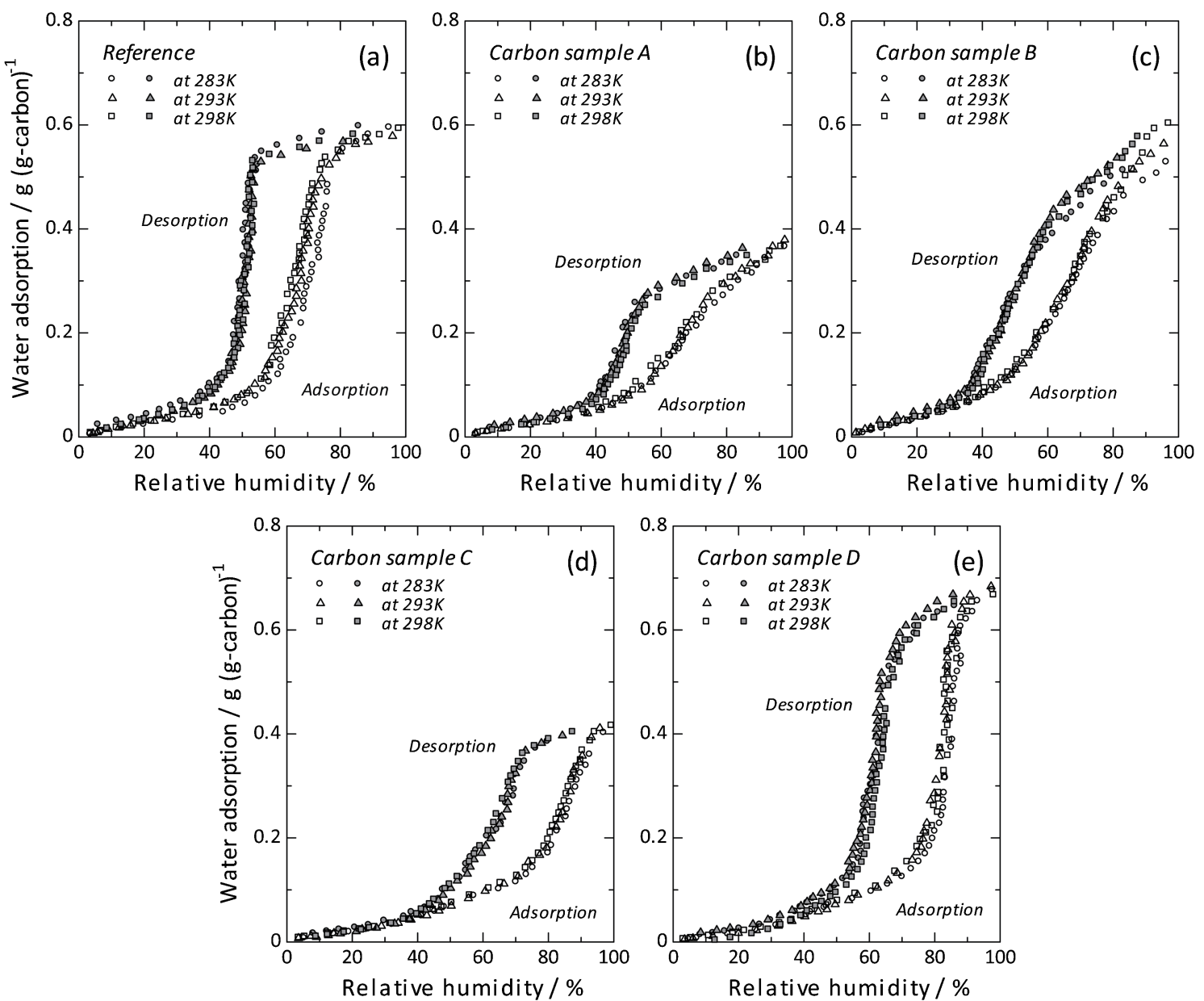

Fig. 3. Water adsorption and desorption isotherms of the reference and templated porous carbon specimens at 283,293 and $298 \mathrm{~K}$.

in the figure are the weight increase due to water adsorption per unit weight of the carbon specimens in the initial dry state. The curve profiles of them were different, but all of the isotherm curves were classified as type $\mathrm{V}$ isotherms according to the IUPAC definitions. Figure 3 shows water isotherms around room temperature $(283,293$ and $298 \mathrm{~K})$ of the reference and templated porous carbon specimens. We found no marked temperature dependence in the isotherms particularly in the templated porous carbon specimens (samples A-D). The adsorption isotherms of the reference activated carbon were slightly unstable against temperature [Fig. 3 (a)] compared with the templated porous carbon specimens with the same equilibration time. The 

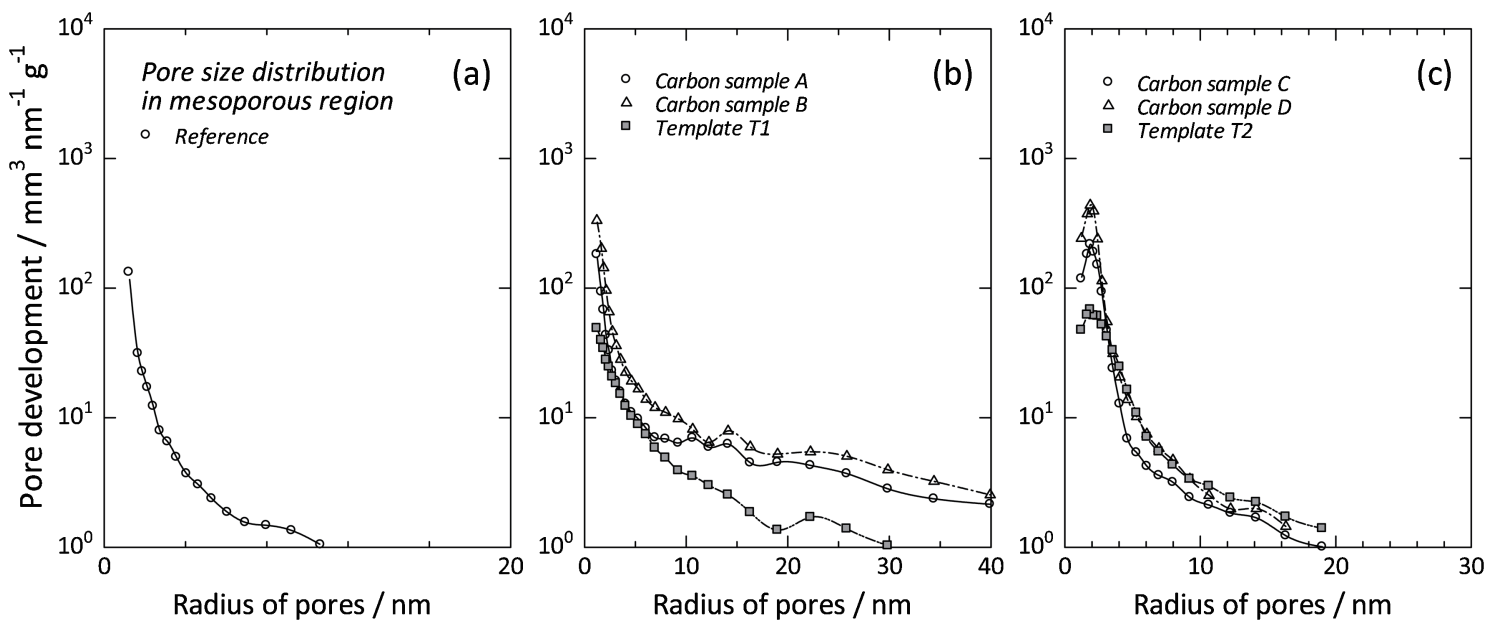

Fig. 4. Pore size distributions and pore development of the reference, templated porous carbon specimens and template materials in this study. Calculated by the Dollimore-Heal (D-H) method in the mesoporous region.

Table 2. Results of elemental analysis and ash measurements of the reference and templated porous carbon specimens. Error of each measurement of elemental analysis is $\leq 0.3$ mass $\%$

\begin{tabular}{ccccc}
\hline \multirow{2}{*}{ Sample } & \multicolumn{4}{c}{ Content/mass \% } \\
\cline { 2 - 5 } & $\mathrm{C}$ & $\mathrm{H}$ & $\mathrm{N}$ & Ash residue \\
\hline Reference & 86.8 & 0.7 & 0.2 & 9.0 \\
$\mathrm{~A}$ & 79.5 & 2.8 & 0.4 & 5.2 \\
$\mathrm{~B}$ & 66.3 & 1.4 & 0.8 & 10.0 \\
$\mathrm{C}$ & 81.3 & 2.2 & 0.2 & 9.3 \\
D & 86.4 & 1.5 & 0.9 & 7.2 \\
\hline
\end{tabular}

instability was assumed to be some attributed to pore development in the mesoporous region in the specimens, because it contributes to transfer and diffusion of molecules of gaseous compounds.

Water adsorption behavior of porous carbons has been commonly discussed from the viewpoint of surface chemical composition, and true density of the templated porous carbon specimens was assumed to be dependent on carbon ingredients (Table 1). However, the features of water isotherms of the templated porous carbon specimens were dependent on template materials rather than carbon ingredients. The specimens synthesized with the same template material and different carbon ingredients showed similar features in water isotherms [Figs. 2(b) and 2(c)]. The results of elemental analysis for CHN and ash measurements of the specimens are described in Table 2, and there were no marked differences in the results particularly on elemental analysis for $\mathrm{H}$ and $\mathrm{N}$ among the templated porous carbon specimens. In addition, they were treated with a solution of strong acid or alkali for dissolution of template materials in the synthesis process, ${ }^{18), 19)}$ and surface functional group of the templated porous carbon specimens is assumed to be almost removed. ${ }^{30)-32)}$

In contrast, the specimens synthesized with the same template material showed similar pore size distribution and pore development (Fig. 4). Thus, pore development of the templated porous carbon specimens markedly affected their water adsorption behavior. As shown in Fig. 2(a), the water adsorption isotherm of common coconut shell activated carbon rose sharply at approximately $60 \%$ relative humidity $(\mathrm{RH})$, and the desorption isotherm dropped off at 50\% $\mathrm{RH}^{33), 34)}$ Climate conditions of $50-60 \% \mathrm{RH}$ and atmospheric temperature around $293 \mathrm{~K}$ are frequent through the whole year in Japan. ${ }^{35), 36)}$ Therefore, leaving the activated carbon products uncontrolled and exposing them to ambient air is undesirable, because handling causes the carbon products to adsorb moisture and significantly reduces their adsorption capacities for harmful substances. In fact, storage of the activated carbon products with drying reagents in desiccators or air conditioning is desirable for effective use of the products as adsorbent materials. On the other hand, as shown in Fig. 2(c), the water adsorption isotherms of samples $\mathrm{C}$ and $\mathrm{D}$ rose sharply at approximately $80 \% \mathrm{RH}$, and the desorption isotherms dropped at $60 \%$ RH. Figure 5 shows the isotherms of the reference and templated porous carbon specimens for cyclohexane, which is a typical indicative substance for organic vapor adsorption by activated carbon, ${ }^{37)}$ at $293 \mathrm{~K}$. In the figure, the specimens adsorbed organic vapor from low concentration or pressure, and the templated porous carbon materials were sufficiently effective as adsorbents for organic vapors.

The results indicate the possibility of application of the templated porous carbon specimens as effective adsorbates that are not susceptible to moisture, particularly in the Japanese climate. In addition, samples $\mathrm{C}$ and $\mathrm{D}$ may also be applicable as humidity control materials in higher humidity regions compared with common activated carbon.

We have synthesized several kinds of templated porous carbon material using 2 kinds of natural allophanic soil purchased in Japan as template materials. We used $\mathrm{D}(+)$-glucose, furfuryl alcohol and brown sugar as carbon ingredients. The specimens had some comparable $\mathrm{N}_{2}$-BET specific surface areas and adsorption capacities compared with common coconut shell activated carbon as a reference. On the other hand, the templated porous carbon specimens had different features in water isotherms around room temperature $(283,293$ and $298 \mathrm{~K})$. The features were dependent on template material rather than carbon ingredients. Consequently, pore development of the templated porous carbon specimens markedly affected their water adsorption behavior. Some of the templated porous carbon specimens indicated the possible applicability of the specimens as effective adsorbents that are not susceptible to moisture. They may also be applicable as humidity control materials in regions with high humidity. 

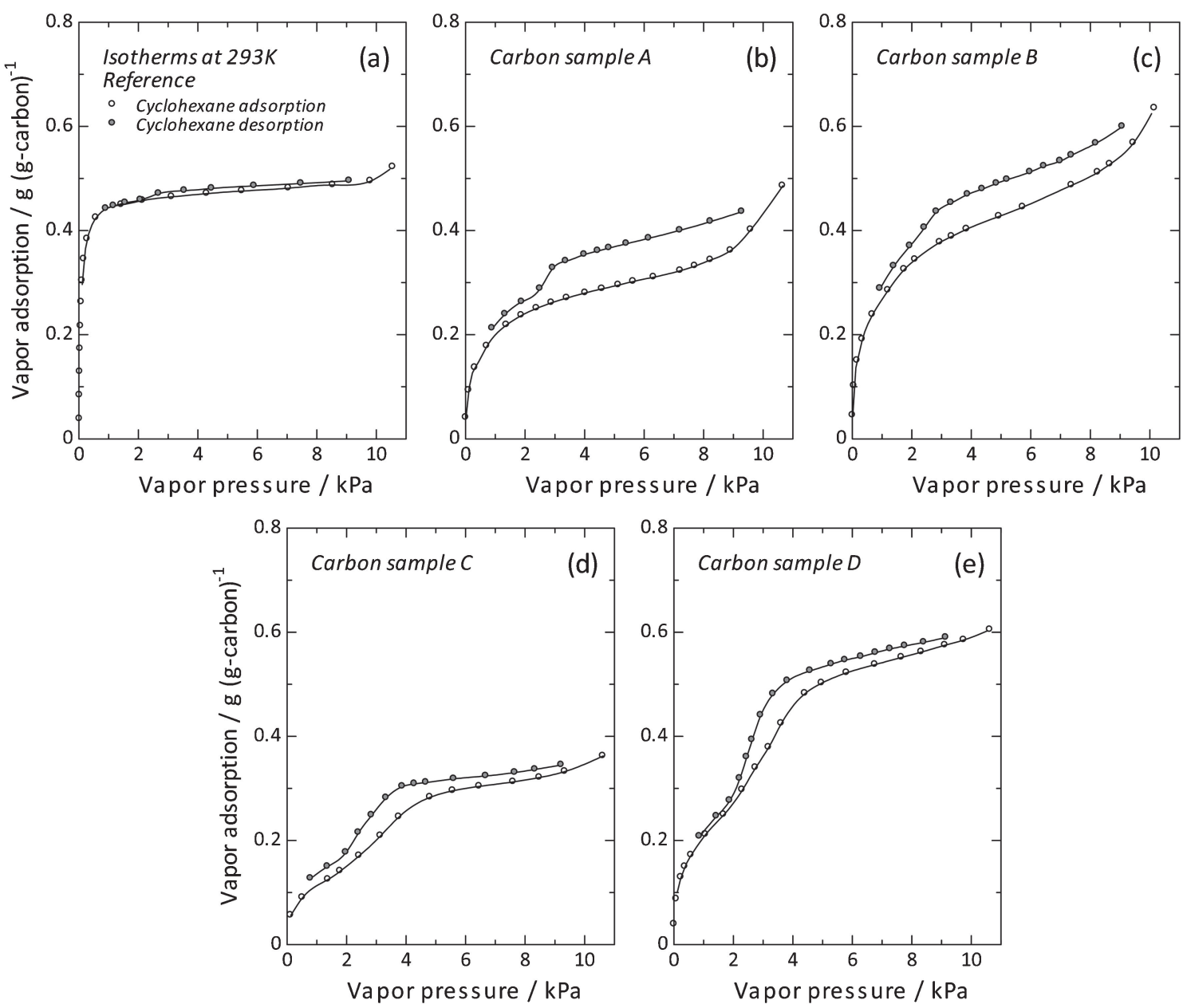

Fig. 5. Cyclohexane vapor adsorption and desorption isotherms of the reference and templated porous carbon specimens at $293 \mathrm{~K}$.

Acknowledgement The results in this report were partly supported by Grant-in-Aid for Young Scientists (B) 20710065, The Ministry of Education, Culture, Sports, Science and Technology (MEXT, Japan).

\section{References}

1) H. L. McDermot and J. C. Arnell, J. Phys. Chem., 58, 492-498 (1954).

2) G. O. Nelson, A. N. Correia and C. A. Harder, Am. Ind. Hyg. Assoc. J., 37, 280-288 (1976).

3) G. O. Nelson and A. N. Correia, Am. Ind. Hyg. Assoc. J., 37, 514-525 (1976).

4) E. S. Moyer, Am. Ind. Hyg. Assoc. J., 44, 46-51 (1983).

5) M. D. Werner, Am. Ind. Hyg. Assoc. J., 46, 585-590 (1985).

6) L. A. Jonas, E. B. Sansone and T. S. Farris, Am. Ind. Hyg. Assoc. J., 46, 20-23 (1985).

7) H. J. Cohen, E. T. Zellers and R. P. Garrison, Am. Ind. Hyg Assoc. J., 51, 575-580 (1990).

8) E. S. Moyer, J. A. Peterson and C. Calvert, Appl. Occup. Environ. Hyg., 10, 769-775 (1995).

9) H. Abiko, M. Furuse and T. Takano, Ind. Health, 48, 52-60 (2010).

10) H. Abiko, M. Furuse and T. Takano, Ind. Health, 48, 427-437 (2010).

11) H. Abiko, TANSO, 2011, 133-143 (2011) [in Japanese].

12) H. Abiko, TANSO, 2011, 185-190 (2011) [in Japanese].

13) K. Kaneko, Y. Hanzawa, T. Iiyama, T. Kanda and T. Suzuki,
Adsorption, 5, 7-13 (1999).

14) D. D. Do and H. D. Do, Carbon, 38, 767-773 (2000).

15) D. D. Do, S. Junpirom and H. D. Do, Carbon, 47, 1466-1473 (2009).

16) R. Mann, H. N. S. Yousef, D. K. Friday and J. J. Mahle, Adsorption, 1, 253-264 (1995).

17) T. Iiyama, M. Ruike and K. Kaneko, Chem. Phys. Lett., 331, 359-364 (2000).

18) H. Abiko, J. Ceram. Soc. Japan, 115, 751-756 (2007).

19) H. Abiko, Trans. Mater. Res. Soc. Jpn., 33, 1-8 (2008).

20) H. Abiko and Y. Shinohara, Trans. Mater. Res. Soc. Jpn., 30, 607-613 (2005).

21) J. Lee, S. Yoon, T. Hyeon, S. M. Oh and K. B. Kim, Chem. Commun. (Camb.), 2177-2178 (1999).

22) R. Ryoo, S. H. Joo and S. Jun, J. Phys. Chem. B, 103, 77437746 (1999).

23) K. Kamegawa and H. Yoshida, J. Mater. Sci., 34, 3105-3108 (1999).

24) S. Han, K. Sohn and T. Hyeon, Chem. Mater., 12, 3337-3341 (2000).

25) T. Kyotani, Carbon, 38, 269-286 (2000).

26) C. J. Meyers, S. D. Shah, S. C. Patel, R. M. Sneeringer, C. A. Bessel, N. R. Dollahon, R. A. Leising and E. S. Takeuchi, J. Phys. Chem. B, 105, 2143-2152 (2001).

27) Z. X. Ma, T. Kyotani and A. Tomita, Carbon, 40, 2367-2374 (2002).

28) S. Brunauer, L. S. Deming, W. E. Deming and E. Teller, J. Am. Chem. Soc., 62, 1723-1732 (1940). 
29) S. J. Gregg and K. S. W. Sing, "Adsorption, Surface Area and Porosity", 2nd Ed., Academic Press, London (1982).

30) H. P. Boehm, Carbon, 32, 759-769 (1994).

31) H. P. Boehm, Carbon, 40, 145-149 (2002)

32) H. Oda, M. Kishida and C. Yokokawa, Carbon, 19, 243-248 (1981).

33) H. Abiko, Sangyo Eiseigaku Zasshi, 52, 216-218 (2010) [in Japanese].

34) H. Abiko, TANSO, 2011 127-132 (2011).

35) National Astronomical Observatory of Japan Ed "Monthly
Average of Ambient Temperature. In: Rika Nenpyo (Chronological Scientific Tables) 2010", Maruzen, Tokyo, pp. 176-177 (2009)[in Japanese].

36) National Astronomical Observatory of Japan Ed "Monthly Average of Ambient Relative Humidity. In: Rika Nenpyo (Chronological Scientific Tables) 2010", Maruzen, Tokyo, pp. 216-217 (2009) [in Japanese].

37) M. Furuse, S. Kanno, T. Takano and Y. Matsumura, Ind. Health, 39, 1-7 (2001) 